\title{
Wind enhances differential air advection in surface snow at sub-meter scales
}

\author{
Stephen A. Drake ${ }^{1}$, John S. Selker ${ }^{2}$, and Chad W. Higgins ${ }^{2}$ \\ ${ }^{1}$ College of Earth, Ocean and Atmospheric Sciences, Oregon State University, Corvallis, 97333, USA \\ ${ }^{2}$ Biological and Ecological Engineering, Oregon State University, Corvallis, 97333, USA \\ Correspondence to: Stephen A. Drake (stephenadrake@gmail.com)
}

Received: 27 January 2017 - Discussion started: 14 March 2017

Revised: 4 July 2017 - Accepted: 24 July 2017 - Published: 5 September 2017

\begin{abstract}
Atmospheric pressure gradients and pressure fluctuations drive within-snow air movement that enhances gas mobility through interstitial pore space. The magnitude of this enhancement in relation to snow microstructure properties cannot be well predicted with current methods. In a set of field experiments, we injected a dilute mixture of $1 \%$ carbon monoxide $(\mathrm{CO})$ and nitrogen gas $\left(\mathrm{N}_{2}\right)$ of known volume into the topmost layer of a snowpack and, using a distributed array of thin film sensors, measured plume evolution as a function of wind forcing. We found enhanced dispersion in the streamwise direction and also along low-resistance pathways in the presence of wind. These results suggest that atmospheric constituents contained in snow can be anisotropically mixed depending on the wind environment and snow structure, having implications for surface snow reaction rates and interpretation of firn and ice cores.
\end{abstract}

\section{Introduction}

Atmospheric pressure changes over a broad range of temporal and spatial scales stimulate air movement in near-surface snow pore space (Clarke et al., 1987) that redistributes radiatively and chemically active trace species (Waddington et al., 1996) such as $\mathrm{O}_{3}$ (Albert et al., 2002), OH (Domine and Shepson, 2002) and NO (Pinzer et al., 2010), thereby influencing their reaction rates. Pore space in snow is saturated within a few millimeters of depth in the snowpack that does not have large air spaces (Neumann et al., 2009), so atmospheric pressure changes induce interstitial air movement that enhances snow metamorphism (Calonne et al., 2015; Ebner et al., 2015) and augments vapor exchange between the snowpack and atmosphere. The relative influences of different pressure-driven processes in the near-surface snowpack are not well understood but are important to distinguish because different processes disperse water vapor and trace species with different signatures. Pressure-driven air movement in snow pore space has been generally termed "pressure pumping" (Massmann and Frank, 2006) or more specifically "wind pumping" (Colbeck, 1989; Clarke and Waddington, 1991; Albert et al., 2002) in circumstances where localized wind characteristics strongly impact variability in the pressure field. To clarify the importance of discriminating the influence of advection relative to diffusion in snow pore space, we briefly describe dominant in-snow processes forced by atmospheric pressure changes.

In his foundational publication on the topic of wind pumping, Colbeck (1989) described how atmospheric pressure changes drive a variety of in-snow processes. Towards the low frequency end of the pressure change continuum, synoptic weather evolution imparts approximately hydrostatic surface pressure changes over multi-day time spans (Wallace and Hobbs, 2006). As a synoptic-scale high-pressure system builds over a given site, compression of the air column pushes air that was formerly just above the snowpack into the snowpack. Correspondingly, as the high-pressure system weakens over the site, the air column expands, and air that formerly was contained in the near-surface snow pore space translates into the atmosphere. Each high-low pressure transition corresponds to a single "breath" by the snowpack that vertically exchanges air contained in the nearsurface pore space of the snowpack with air just above it. Although the amplitude of synoptic pressure changes is large $(\sim 4000 \mathrm{~Pa})$ relative to turbulently generated pressure 
changes (<100 Pa; Paw U et al., 2004; Drake et al., 2016), they are infrequent and therefore cause negligible snowatmosphere fluxes (Bartlett and Lehning, 2011). Synoptic pressure changes have been linked to mixing in firn, however (Severinghaus et al., 2010), and may also leave an isotopic signature of synoptic intensity in ice cores (Buizert and Severinghaus, 2016). Filtering of fine particle atmospheric constituents by snow (Waddington et al., 1996) at synoptic frequencies would correspondingly be gradual and relevant over seasonal and longer timescales.

By contrast, localized pressure changes due to wind blowing over surface features or caused by wind variability (turbulence) generate pressure changes with much higher frequency, smaller spatial extent and smaller amplitude than synoptic-scale pressure changes. Wind blowing steadily over surface features generates localized, quasi-static pressure gradients, and air in snow moves in response to these wind-induced pressure gradients (Colbeck, 1989). These topographically induced pressure gradients generate quasistationary circulation patterns that transport gases (Massman and Frank, 2006) and form zones of preferential sublimation and deposition (Albert, 2002) and therefore have a discernable advective signature. Turbulently generated pressure fluctuations induce air movement in snow (Drake et al., 2016), but the response of air contained in snow pore space to turbulent forcing above the snow or above permeable media in general is not fully understood despite considerable effort (de Lemos et al., 2006; Mößner and Radespiel, 2015; and many others). Classical boundary layer theory (Beavers and Joseph, 1967) suggests that the time-averaged pressure gradient in permeable media such as snow would generate a Darcian flow (advection) aligned with the pressure gradient. Unlike the advection signature for topographic forcing, the turbulence signature does not exhibit quasi-static circulation patterns. Similar to turbulence, advection through a mechanically dispersive medium such as snow dissipates a concentration gradient (Scheidegger, 1954) but in this case preferentially spreads a plume more aggressively in the downstream direction.

Airflow through snow is regulated by intrinsic permeability, which is a proportionality constant in Darcy's law and is a measure of the interconnectedness of the pore space. Snow permeability is difficult to measure in field conditions but is a fundamental input parameter to model in-snow advection (Darcian flow). Currently accepted sampling techniques to obtain snow permeability include both direct measurements and indirect measurements that infer permeability from some other snow property such as specific surface area (SSA) and/or snow density. Sub-liter-sized snow samples are typically used to obtain direct permeability measurements with a flow-through permeameter (Courville et al., 2007), with microtomography (Calonne et al., 2012) and when using an integrating sphere to obtain SSA measurements and infer permeability (Gallet et al., 2009). A near-infrared photography technique that infers SSA from reflectance (Painter et al., 2007; Tape et al., 2010) acquires pore space characteristics over larger areas but only in two dimensions, as do stereological measurements (Davis et al., 1987; Matzl and Schneebeli, 2010) for smaller sample sizes. Active acoustic techniques for inferring large-footprint, volume-averaged permeability of snow cover have shown potential (Albert, 2001; Drake et al., 2017), but these techniques are unproven for standard data collection. Methods that correlate SSA and snow density with intrinsic permeability facilitate relating small sample sizes to larger snow volumes. However, none of these standard techniques sample intrinsic permeability of large snow volumes and they therefore do not capture macroscopic changes in permeability due to snow inhomogeneities and fractures. The consequence of neglecting the variability of intrinsic permeability for modeling airflow through snow is not known.

The presence of in-snow advection has been experimentally inferred from natural convection (Sturm and Johnson, 1991), from temperature changes caused by forced ventilation (Albert and Hardy, 1995; Sokratov and Sato, 2000) and from $\mathrm{CO}_{2}$ flux measurements (Bowling and Massman, 2011), but few measurements of natural air advection in snow have been obtained (Albert and Shultz, 2002; Huwald et al., 2012). Bulk $\mathrm{CO}_{2}$ flux measurements by Massmann and Frank (2006), Seok et al. (2009), and Bowling and Massman (2011) have increased our appreciation for the role of wind pumping in enhancing soil-snow-atmosphere exchange beyond that given by diffusion but lack the spatial and temporal granularity needed to discern between the relative roles of in-snow transport processes. A deeper understanding of the processes that link atmospheric pressure forcing to the in-snow pore space response is needed if we are to accurately model how water vapor and chemically and radiatively active trace species propagate into, through and out of the snow pore space.

The overarching goal of this experiment is to measure wind forcing above the snow and simultaneously perform high-spatial and temporal measurements of the evolution of a trace gas release in snow such that we can link wind forcing with in-snow response. Our strategy is to compare model simulations that implement a solution of the advectiondiffusion equation for homogenous, permeable media with experimental measurements of dispersion of a tracer gas in snow. Anisotropy of seasonal snow has been evaluated (Calonne et al., 2012), and we do not assume snow homogeneity in our experimental design. Rather, we compare field experiments with an analytical solution for dispersion in homogenous media to highlight the influence of snow inhomogeneities. Step changes in permeability between successive snow layers further complicate the relationship between wind forcing and the in-snow advective response (Colbeck, 1991; Albert, 1996). To minimize the complicating influence of snow layering, we confined this exploration to the topmost snow layer that had been deposited by a significant snowfall event. We therefore focus this investigation on the effect that 
wind blowing over snow has on air movement within the topmost layer of a snowpack.

\section{Methods}

\subsection{Snow picket description}

The measurement network was composed of 28 thin-film Applied Sensor MLC carbon monoxide (CO) sensors with a detection range spanning 4 orders of magnitude (from 0.5 to 500 ppmv). To measure $\mathrm{CO}$ gas at well-known positions in the snow, seven $\mathrm{CO}$ sensors were mounted in $15 \mathrm{~cm}$ intervals on each of four tapered poles (or snow pickets, Fig. 1) with dimensions $1 \mathrm{~m} \times 5 \mathrm{~cm}$. We deployed the snow pickets in the topmost snow layer that was at least $20 \mathrm{~cm}$ deep to minimize the influence of the profile of the instruments in disrupting interstitial flow. The pickets were inserted horizontally into the snow, forming a rectangular sensor grid. Silicone tubing strung down the center of each picket to an outlet opposite the $\mathrm{CO}$ sensors provided a means to deliver the $\mathrm{CO}$ gas to a well-known position in the snow. This same system was also used in Huwald et al. (2012), and we refer readers to that document for a thorough explanation of materials, manufacturing and wiring requirements.

Data from the $28 \mathrm{CO}$ sensors were acquired on two synchronized Campbell Scientific CR1000 loggers at $1 \mathrm{~min}$ intervals. $\mathrm{CO}$ gas was delivered fast enough relative to the 1 min measurement interval to approximate an instantaneous release. A Campbell Scientific Irgason ultrasonic anemometer captured 3-D wind components at $20 \mathrm{~Hz}$ approximately $1 \mathrm{~m}$ above the snow. The $1 \mathrm{~min}$ wind speed and direction averages were computed by post-processing the highfrequency data. The experiment configuration is presented as a schematic diagram in Fig. 2.

\subsection{Tracer gas}

Consistent with Huwald et al. (2012), we chose CO as a tracer gas because its molecular weight is very close to that of air, so it is nearly neutrally buoyant. Neutral buoyancy ensures that gravitational effects do not influence plume evolution, although neutral buoyancy is not strictly achieved for this experiment. In practice, neutral buoyancy is difficult to achieve because the air space in snow is saturated and therefore more buoyant than dry air but less buoyant than nitrogen gas $\left(\mathrm{N}_{2}\right)$. CO can be safely handled when used in small quantities, has low background concentration and low water solubility. This latter consideration is important because snow grains may be coated with a thin film of liquid water, even at sub-freezing temperatures (Boxe and Saiz-Lopez, 2009). A mixture of $1 \% \mathrm{CO}$ in $99 \% \mathrm{~N}_{2}$ provided sufficient concentration for sensor detection.

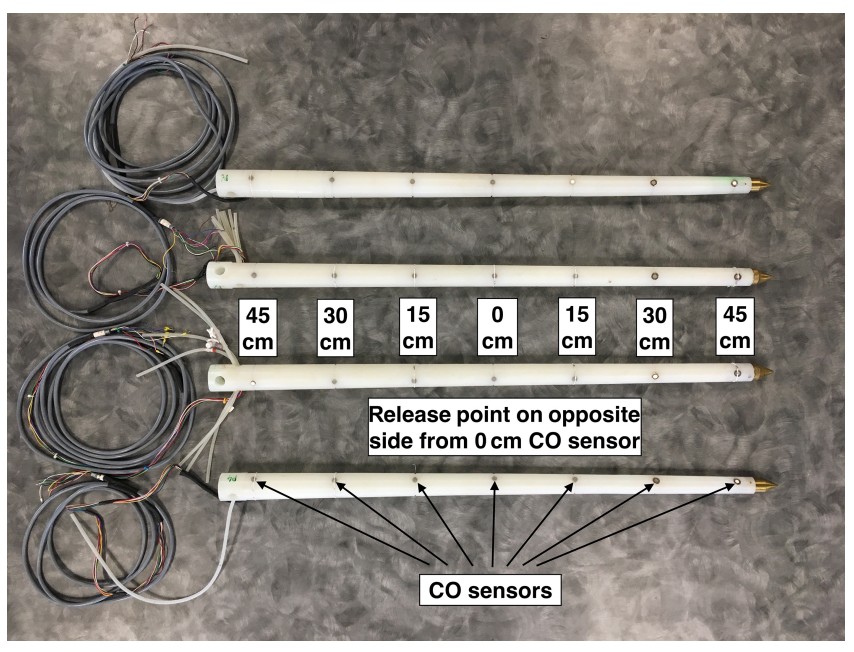

Figure 1. Four $1 \mathrm{~m}$ snow pickets, each mounted with $7 \mathrm{CO}$ sensors at $15 \mathrm{~cm}$ spacing. Along-picket distances of the $\mathrm{CO}$ sensors from the central CO sensor are labeled in the picture. Carbon monoxide was released through tubing that exited the picket opposite the central $(0 \mathrm{~cm}) \mathrm{CO}$ sensor on one of the pickets.

\subsection{Site description}

The system represented in Fig. 2 was deployed at three locations: Santiam Pass, Oregon (elevation: $1468 \mathrm{~m}$ ); Dutchman Flat Sno-Park, Oregon (elevation: $1905 \mathrm{~m}$ ); and Storm Peak Lab (SPL), Mt. Werner, Colorado (elevation: $3220 \mathrm{~m}$ ) during winter and spring seasons of 2014 and 2015. These sites span a broad range of wind forcing and snow density from 227 to $430 \mathrm{~kg} \mathrm{~m}^{3}$. The Santiam Pass and Dutchman Flat sites were nearly flat, while the SPL deployment site was located on a gradual slope ( $\sim 17 \%$ average slope over $100 \mathrm{~m}$ distance, as determined from Google Earth) with a western aspect. For each deployment we mounted a sonic anemometer at $\sim 1 \mathrm{~m}$ height on a low-profile tower with the sonic transducer facing into the prevailing wind. The windward side of the tower was kept free of disturbance.

\subsection{Data selection criteria}

Data were selected from a larger data set composed of 24 releases in 10 different snow conditions over two field seasons. Quality control criteria excluding some data were weatherrelated instrument issues such as sonic anemometer transmission losses due to snow, rain or riming; excessive gas leakage around the release picket; gas leakage at a tube fitting; and excessive icing, wetting, or temperature changes of $\mathrm{CO}$ sensors. The dual requirements that the $\mathrm{CO}$ sensors needed to be ice-free with minimal temperature variations for optimal operation restricted deployment time spans to no more than several hours. Between deployments the sensors were air dried in a lab environment to return them to an optimal operational state. Immediately prior to each deployment, we 


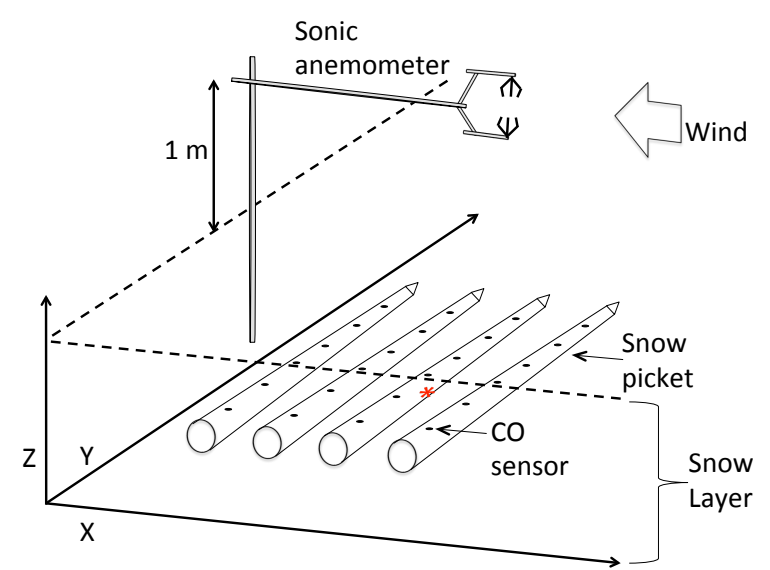

Figure 2. Diagram of the experimental setup showing relative positions of the sonic anemometer and snow pickets. The red asterisk marks the release point on the bottom of one of the snow pickets. The CO sensors on four snow pickets define an $x-y$ plane that is retained in subsequent figures.

determined the prevailing wind direction so that the pickets could be inserted approximately perpendicular to the wind direction. This orientation maximized the sensor network's ability to resolve a plume propagating downwind and was achieved for all cases except cases 13 and 14, which experienced a wind shift during instrument setup. With the exception of case 12 the surface snow layer was deposited by a single storm event and was sufficiently deep to position the sensor pickets in a discrete snow layer. Cases 7 through 11 were acquired in a snow layer that had undergone equilibrium snow metamorphism forming spheroidal snow grains. Snow density was acquired with a $1000 \mathrm{~cm}^{3}$ Snowmetrics RIP 1 Cutter and weighed with a digital gram scale.

\subsection{Calibration}

We built a calibration chamber (Fig. 3) into which we could simultaneously place all four pickets and verify the operational capabilities of the Applied Sensor MLC CO sensors that we used for this experiment. We found through trial and error that the $\mathrm{CO}$ sensors are sensitive to both humidity and temperature. Furthermore, we found that sensor sensitivity decreases when exposed to the same $\mathrm{CO}$ concentration over a long period (>10 min). To compensate for these deficiencies we transported the calibration chamber to the Santiam Pass warm snow site where the surface snow layer was $-1{ }^{\circ} \mathrm{C}$ and to the Storm Peak Lab cold snow site where the surface layer temperature averaged $-6^{\circ} \mathrm{C}$ during the calibration time period. The procedure was to shovel some snow into the chamber then insert the pickets into support collars that suspended the pickets in the chamber above the snow. The chamber was sealed and a measured volume of $\mathrm{CO}$ was introduced. A fan inside the calibration chamber facilitated thoroughly mixing the air. Measurements were acquired at $1 \mathrm{~min}$ intervals

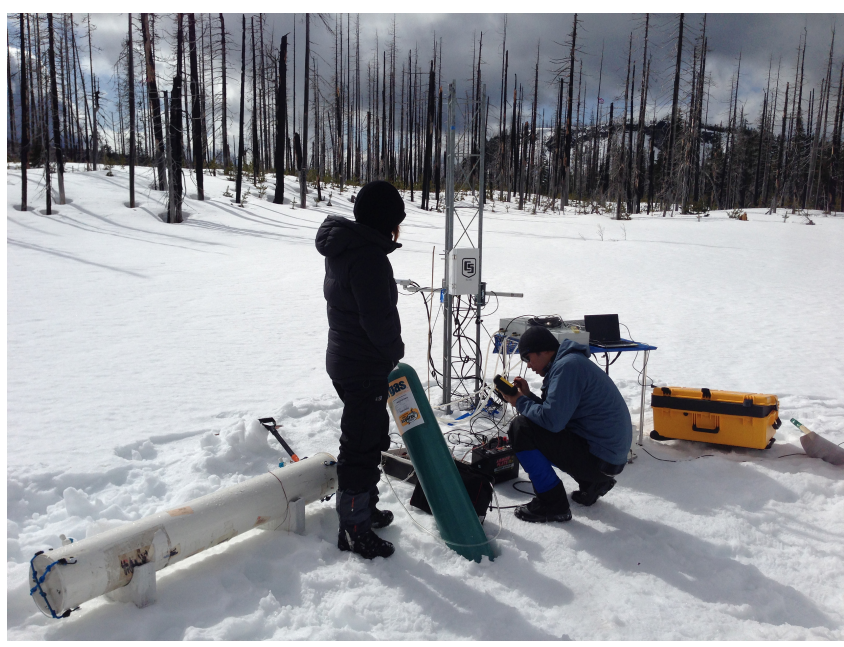

Figure 3. Picture of the calibration chamber (white PVC conduit) at the Santiam Pass site. Snow pickets are placed in low-profile collars to keep them separated within the chamber. Silicone is used to seal the chamber endplates, and duct seal is used to seal air gaps around the $\mathrm{CO}$ sensor wiring as it passes through the endplates. A dilute mixture of CO gas (green tank) is introduced into the chamber through an Aalborg GFM17 mass flowmeter and mixed by a fan within the chamber. $\mathrm{CO}$ concentration as measured by each sensor is acquired on a CR1000 logger (mounted in a weather-resistant case) for $\sim 10 \mathrm{~min}$ at each concentration measured. After each concentration measurement, the $\mathrm{CO}$ gas mixture is evacuated to minimize sensor saturation.

with two Campbell Scientific CR1000 loggers until sensor response was documented. The chamber was then opened on both ends for $\sim 30 \mathrm{~min}$ to allow the chamber to fully evacuate. This procedure was repeated for the next measurement. This calibration procedure was time consuming and we were therefore not able to perform it in concert with field deployments. Although the maximum recommended operating concentration is 500 ppmv, tests revealed a linear response that consistently exceeded 1000 ppmv. Measured gas concentration at the sensor nearest the release point typically exceeded 1000 ppmv, but this sensor was not used for analysis and therefore did not influence experimental results. Further calibration details can be found in Huwald et al. (2012).

\section{Data analysis}

\subsection{Methodology}

We used two methods to analyze the results. For the first method, we applied calibration coefficients from either warm or cold snow calibrations to voltage measurements and derived $\mathrm{CO}$ concentration for each sensor at each time step. From these data we calculated the position of the center of mass in order to determine plume propagation speed. In the second method, we calculated the time required to 
reach maximum concentration at each sensor as a measure of plume propagation. Deviations from the simulated concentration give a measure of the influences of advection and snow heterogeneity.

A solution of the 3-D advection-diffusion equation for a point source (with 2-D advection) is (Socolofsky and Jirka, 2005)

$$
\begin{aligned}
& C(x, y, z, t)=\frac{M}{4 \pi t \sqrt{4 \pi t D_{x} D_{y} D_{z}}} \exp \\
& \quad\left[-\frac{\left(\left(x-x_{1}\right)-U t\right)^{2}}{4 t D_{x}}-\frac{\left(\left(y-y_{1}\right)-V t\right)^{2}}{4 t D_{y}}-\frac{\left(z-z_{1}\right)^{2}}{4 t D_{z}}\right],
\end{aligned}
$$

where $C(x, y, z, t)$ is concentration, $M$ is mass, $U$ and $V$ are horizontal wind components, $D_{x, y, z}$ are diffusivity along the $x, y$ and $z$ axes, and $t$ is time. For idealized homogenous snow (constant $D_{x, y, z}$ ) we can differentiate Eq. (1) with respect to time and set this result equal to zero to find the streamwise advection velocity:

$\sqrt{U^{2}+V^{2}}=\sqrt{\frac{r^{2}-6 D t_{\mathrm{MAX}}}{t_{\mathrm{MAX}}^{2}}}$,

where $r$ is the distance from the release point to a given position and $t_{\mathrm{MAX}}$ is the time interval between the release time and the time at which maximum concentration is reached at that position. For zero wind velocity

$D=\frac{r^{2}}{6 t_{\mathrm{MAX}}}$.

Equation (3) permits calculation of the horizontal diffusivity as a function of the time required between the initial release and the maximum measured concentration at each sensor location, assuming zero air velocity in snow. Non-zero interstitial air velocity and snow heterogeneity manifest as spatial variations in diffusivity. For each $\mathrm{CO}$ release, we measured $\mathrm{CO}$ concentration as a function of time and distance from the release point to find $t_{\mathrm{MAX}}$ for each sensor. Using Eq. (3) we then calculated the diffusivity for each sensor and subtracted these values from a mono-valued diffusivity of $2.56 \times 10^{-5} \mathrm{~m}^{2} \mathrm{~s}^{-1}$ consistent with snow (Huwald et al., 2012) to derive a residual that is an approximation of winddriven dispersion enhancement. This technique has the advantage that absolute concentration is irrelevant so the result is insensitive to sensor calibration error.

\subsection{Caveat}

We will not attempt to compare the vertical diffusivity with the horizontal diffusivity, as that comparison would require a three-dimensional measurement network. Calonne et al. (2012) found that snow anisotropy causes differences between horizontal and vertical diffusivity for air in snow. We postulate that in-snow vertical transport enhancement increases as wind ventilation increases (Albert and Shultz,
2002). For this reason, we expect that our computations using Eq. (3) will be systematically low, the degree to which depends on the difference between the horizontal and vertical diffusivity and the relative wind enhancement of in-snow air motion in the horizontal and vertical directions. As our measurements will show, a distinct snow layer is not homogenous, and this method will highlight macroscopic channels of inhomogeneity.

\section{Results}

\subsection{Model simulations}

Results in a horizontal plane from an advection-diffusion model assuming isotropic media with a diffusivity of $2.56 \times$ $10^{-5} \mathrm{~m}^{2} \mathrm{~s}^{-1}$ are shown in Fig. $4 \mathrm{a}$. An instantaneous release at the origin (marked by a red asterisk) spreads in time, and the red dots mark the locations of point measurements at 15 , 30 and $45 \mathrm{~cm}$ from the release point. Half-hour time series of the simulated concentrations at these three locations are shown in Fig. 4b. The three time series in Fig. 4b delineate "breakthrough curves" that share a distinctive shape with a rapidly rising concentration to a peak followed by gradual decay. In a purely diffusive environment the breakthrough curve of each successively distant point from the release location is contained within curves defined by closer points as in Fig. 4b. Isotropic molecular diffusion spreads a plume in all directions but the centroid of mass remains stationary over time. On the other hand, advection translates the centroid. In Fig. 4c and d we have imposed an advective flow of $0.5 \mathrm{~mm} \mathrm{~s}^{-1}$ oriented along the positive $x$ axis. For the corresponding set of breakthrough curves in Fig. 4d, the traces cross at some point in time if advection is sufficiently fast relative to diffusion. By comparing breakthrough curves derived from field experiments with simulations, we can estimate the relative influences of dispersive processes. In this idealized description we do not account for snow heterogeneity, which enhances diffusion in regions of higher porosity, potentially leading to centroid displacement.

\subsection{Field data}

The results presented in this paper are based on $14 \mathrm{CO}$ releases selected from five snow conditions. Distance between snow pickets, picket depths, release volumes, and associated weather conditions and surface layer snow metrics are detailed in Table 1. With the exception of case 12, pickets were placed in a layer of snow generated by a single snow event such that we could minimize the effect of snow layering on dispersion. Release volume was measured with an Aalborg GFM17 mass flowmeter (range 0-15 SLPM) for cases 1 through 11 and with a precision sampling Magnum series $500 \mathrm{~mL}$ gas-tight syringe for cases 12 through 14 . For case 12, the pickets were placed below an ice layer that was overlain by surface snow generated by a single storm event. 

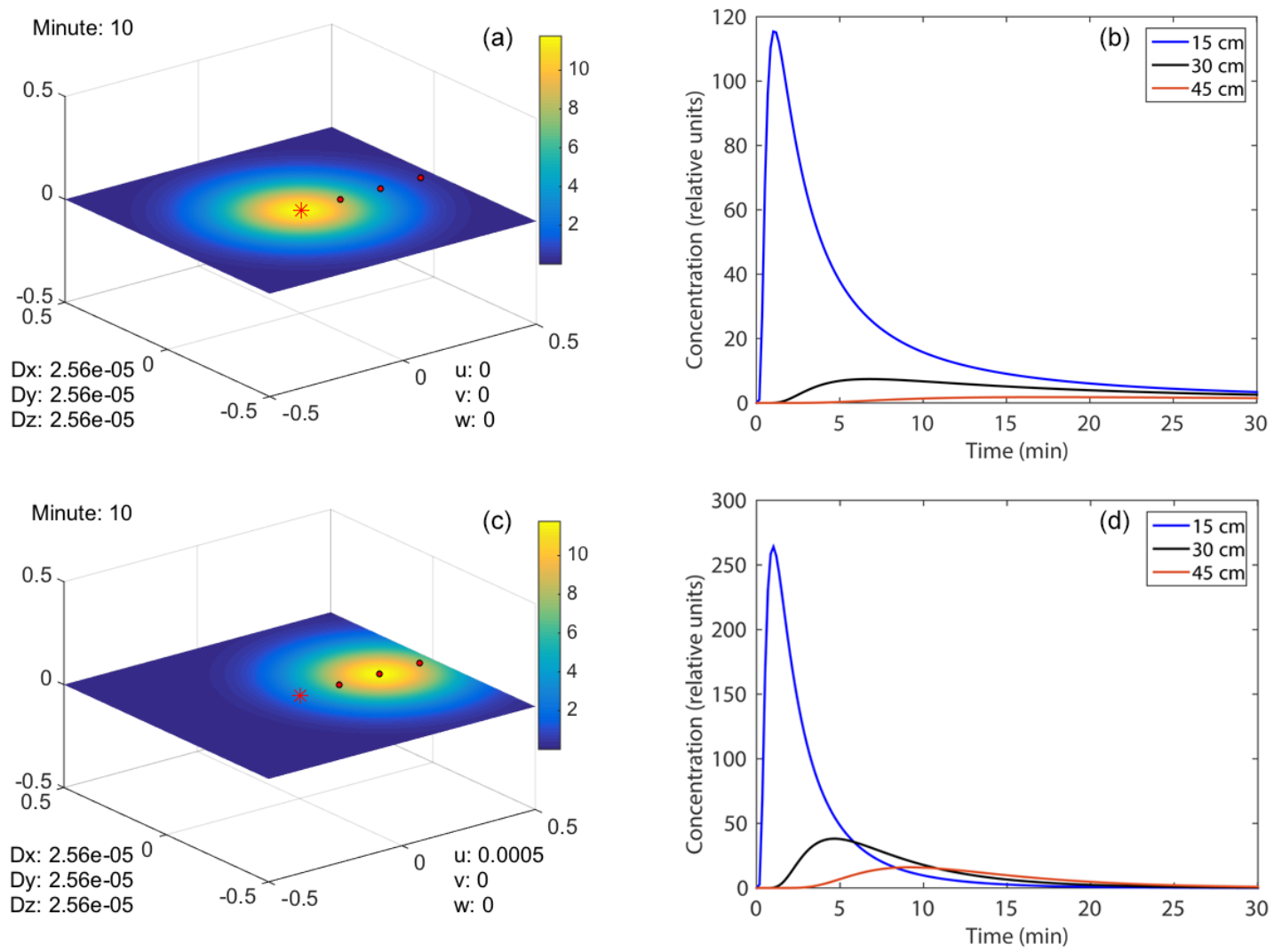

Figure 4. Horizontal cross section of simulated plume dispersion in a purely diffusive case over a $1 \mathrm{~m}^{3}$ volume (a) and the associated breakthrough curve (b) and for a diffusive-advective case (c) with the associated breakthrough curve (d). The red asterisks in panels (a) and (c) mark the plume release point. For the advective-diffusive scenario, plume concentration is greater at the $30 \mathrm{~cm}$ position than the $15 \mathrm{~cm}$ position after $10 \mathrm{~min}$.

Cases 1-11 were calibrated using a warm snow calibration at Santiam Pass, and cases 12-14 were calibrated with a cold snow calibration at Storm Peak Lab. At each site, we carefully dug a shallow trench, exposing a clean face of the snow layer into which we inserted the sensor-mounted pickets. Once the pickets were placed, we backfilled the snow pit with fresh snow and smoothed the surface to match the surrounding, undisturbed snow level. Snow in the backfilled trench was not measured directly; however, it is possible that disturbing snow in close proximity to the measurement volume could have influence the local pressure field. In Huwald et al. (2012) sensor pickets were placed vertically and the authors noted leakage around the picket perimeter that manifested as enhanced dispersion along the picket axis for low snow density releases. Even with horizontal (and buried) picket placements, we observed indication of leakage for a few cases, but most cases were performed in snow that seated snugly against the pickets, minimizing along-picket leakage.

\subsection{Breakthrough curves}

A picture of the experiment setup for 26 March 2015 is shown in Fig. 5, and the results of CO release R2 are plotted in Fig. 6 (case 14 in Table 1) in the presence of $3.06 \mathrm{~m} \mathrm{~s}^{-1}$ mean wind speed and $227 \mathrm{~kg} \mathrm{~m}^{-3}$ density snow. The breakthrough curves in Fig. $6 \mathrm{~b}$ are smooth and indicative of diffusion-dominated dispersion, yet a subtle advection signature of breakthrough curves crossing each other is evident in Fig. 6b, similar to Fig. 4d. This result shows that an advection signature is evident at approximately $20 \mathrm{~cm}$ depth in mid-tolow-density snow. The maximum concentration measured at the release point in Fig. 6a exceeded the linear calibration range of the $\mathrm{CO}$ sensors. Calibration range exceedance near the release point commonly occurred during releases, but the results presented in this paper do not rely upon release point concentration measurements. Rather, larger releases enabled greater resolution of far field concentration measurements and $t_{\mathrm{MAX}}$ calculations.

\subsection{Effect of wind direction}

For two contrasting cases during the same deployment (19 April 2014), Fig. 7a-d shows the effect of wind on subsurface plume evolution. In case 8 (Fig. 7a-b), prevailing winds were persistent and from the west, whereas for case 11 (Fig. $7 \mathrm{c}-\mathrm{d}$ ) winds were light and variable. The time required 
Table 1. Summary of cases used for this analysis. Wind speed is at $1 \mathrm{~m}$ nominal height. Layer density is the average snow density for a distinct surface snow layer. Horizontal picket spacing and CO sensor depth are listed by picket, ordered left to right as shown in the figures.

\begin{tabular}{|c|c|c|c|c|c|c|c|c|c|c|}
\hline Date & Location & $\begin{array}{l}\text { Surface } \\
\text { layer } \\
\text { density } \\
\left(\mathrm{kg} \mathrm{m}^{-3}\right)\end{array}$ & $\begin{array}{l}\text { Picket } \\
\text { spac- } \\
\text { ing } \\
(\mathrm{cm})\end{array}$ & $\begin{array}{l}\mathrm{CO} \\
\text { sensor } \\
\text { depth } \\
(\mathrm{cm})\end{array}$ & $\begin{array}{l}\text { Case } \\
\text { ID }\end{array}$ & $\begin{array}{l}\text { Release } \\
\text { ID }\end{array}$ & $\begin{array}{l}\text { Release } \\
\text { vol- } \\
\text { ume } \\
\text { L }\end{array}$ & $\begin{array}{l}\text { Mean } \\
\text { wind } \\
\text { speed } \\
\left(\mathrm{m} \mathrm{s}^{-1}\right)\end{array}$ & $\begin{array}{l}\text { Sigma } \\
\text { wind } \\
\text { speed } \\
\left(\mathrm{m} \mathrm{s}^{-1}\right)\end{array}$ & $\begin{array}{l}\text { Meteorological and surface snow } \\
\text { conditions. Air temperature; crystal } \\
\text { type; size; hardness }\end{array}$ \\
\hline $\begin{array}{l}3 \text { Apr } \\
2014\end{array}$ & $\begin{array}{l}\text { Dutchman } \\
\text { Flat, } \\
\text { Oregon }\end{array}$ & 249 & $\begin{array}{l}29 \\
36 \\
28\end{array}$ & $\begin{array}{l}13, \\
14, \\
14 \\
14\end{array}$ & $\begin{array}{l}1 \\
2 \\
3\end{array}$ & $\begin{array}{l}\text { R1 } \\
\text { R2 } \\
\text { R3 }\end{array}$ & $\begin{array}{l}2.00 \\
1.33 \\
2.67\end{array}$ & $\begin{array}{l}1.64 \\
2.45 \\
1.86\end{array}$ & $\begin{array}{l}0.92 \\
1.51 \\
1.10\end{array}$ & 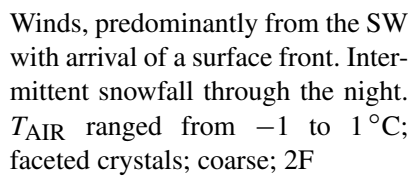 \\
\hline $\begin{array}{l}4 \text { Apr } \\
2014\end{array}$ & $\begin{array}{l}\text { Dutchman } \\
\text { Flat, } \\
\text { Oregon }\end{array}$ & 249 & $\begin{array}{l}11.5 \\
13.5 \\
16\end{array}$ & $\begin{array}{l}6.8 \\
7.0 \\
6.0 \\
6.8\end{array}$ & $\begin{array}{l}4 \\
5 \\
6\end{array}$ & $\begin{array}{l}\text { R3 } \\
\text { R4 } \\
\text { R5 }\end{array}$ & $\begin{array}{l}9.50 \\
6.00 \\
9.50\end{array}$ & $\begin{array}{l}2.55 \\
2.62 \\
2.91\end{array}$ & $\begin{array}{l}1.22 \\
1.22 \\
1.52\end{array}$ & $\begin{array}{l}\text { Winds turning from } \mathrm{SW} \text { to } \mathrm{NW} \\
\text { through the day. Low directional } \\
\text { variability. Clearing weather } \\
\text { through day. } T_{\mathrm{AIR}} \text { ranged from }-1 \\
\text { to } 0^{\circ} \mathrm{C} \text {; faceted crystals; coarse; } 2 \mathrm{~F}\end{array}$ \\
\hline $\begin{array}{l}19 \text { Apr } \\
2014\end{array}$ & $\begin{array}{l}\text { Santiam } \\
\text { Pass, } \\
\text { Oregon }\end{array}$ & 430 & $\begin{array}{l}15.0 \\
17.6 \\
17.0\end{array}$ & $\begin{array}{l}9.0 \\
9.6 \\
9.0 \\
9.0\end{array}$ & $\begin{array}{l}7 \\
8 \\
9 \\
10 \\
11\end{array}$ & $\begin{array}{l}\text { R1 } \\
\text { R2 } \\
\text { R3 } \\
\text { R4 } \\
\text { R5 }\end{array}$ & $\begin{array}{l}2.30 \\
4.00 \\
5.00 \\
6.67 \\
1.17\end{array}$ & $\begin{array}{l}2.83 \\
2.19 \\
1.68 \\
0.75 \\
0.38\end{array}$ & $\begin{array}{l}1.47 \\
1.10 \\
0.92 \\
0.56 \\
0.22\end{array}$ & $\begin{array}{l}\text { Clear day. } T_{\text {AIR }} \text { ranged from }-2 \text { to } \\
5^{\circ} \mathrm{C} \text {; rounded grains, very coarse; } \\
4 \mathrm{~F}\end{array}$ \\
\hline $\begin{array}{l}24 \mathrm{Mar} \\
2015\end{array}$ & $\begin{array}{l}\text { Storm Peak } \\
\text { Lab, } \\
\text { Colorado }\end{array}$ & $\begin{array}{l}\text { Variable, } \\
\text { ice } \\
\text { layer }\end{array}$ & $\begin{array}{l}15.5 \\
14.5 \\
15.0\end{array}$ & $\begin{array}{l}21.0 \\
19.0 \\
16.0 \\
17.0\end{array}$ & 12 & $\mathrm{R} 1$ & 0.20 & 4.05 & 1.40 & $\begin{array}{l}\text { Stormy. } T_{\mathrm{AIR}} \text { ranged from }-7 \text { to } \\
-5^{\circ} \mathrm{C} \text {; faceted crystals; medium; } \\
3 \mathrm{~F}\end{array}$ \\
\hline $\begin{array}{l}26 \mathrm{Mar} \\
2015\end{array}$ & $\begin{array}{l}\text { Storm Peak } \\
\text { Lab, } \\
\text { Colorado }\end{array}$ & 227 & $\begin{array}{l}19.0 \\
19.0 \\
18.0\end{array}$ & $\begin{array}{l}18.0 \\
19.0 \\
19.0 \\
19.0\end{array}$ & $\begin{array}{l}13 \\
14\end{array}$ & $\begin{array}{l}\mathrm{R} 1 \\
\mathrm{R} 2\end{array}$ & $\begin{array}{l}0.20 \\
0.20\end{array}$ & $\begin{array}{l}3.41 \\
3.06\end{array}$ & $\begin{array}{l}0.92 \\
1.07\end{array}$ & $\begin{array}{l}\text { Clear day. } T_{\mathrm{AIR}} \text { ranged from }-5 \\
\text { to }-2{ }^{\circ} \mathrm{C} \text {; faceted crystals; medium; } \\
2 \mathrm{~F}\end{array}$ \\
\hline
\end{tabular}

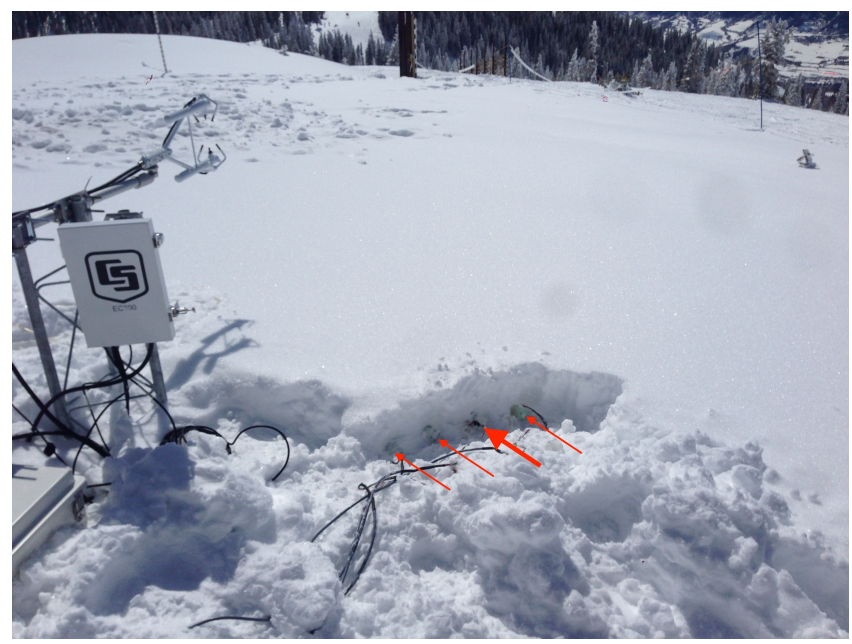

Figure 5. This picture shows the experimental setup for cases 13 and 14 and was taken after the data acquisition period. Red arrows point to the tops of the snow pickets after we removed snow to expose the top and left side of the instrumented snow layer for documentation purposes. The bold red arrow points to the snow picket where the trace gas was released for these two cases. A Campbell Scientific Irgason mounted above the snow pickets acquired horizontal and vertical wind speed and direction at $20 \mathrm{~Hz}$. to reach the maximum concentration for each sensor as described in Eq. (3) is plotted in Fig. 7b and d. For case 8 (Fig. 7b) the plume orients streamwise to the wind, with increased streamwise dispersion relative to cross stream. The plume shape in low-wind case 11 (Fig. 7d) is more circular as would be expected for diffusion-dominated dispersion. We attribute deviations from radial symmetry for lowwind case 11 to snow inhomogeneities. This case comparison shows that an advective signature is evident in at $9 \mathrm{~cm}$ depth in dense $\left(430 \mathrm{~kg} \mathrm{~m}^{-3}\right)$ snow.

The subtle, streamwise plume alignment evident in Fig. $7 \mathrm{a}-\mathrm{b}$ is more easily discriminated with larger $\mathrm{CO}$ releases, an example of which is plotted in Fig. 7e-f. This release was too large to approximate a point release, but it unambiguously shows that the plume aligns in a streamwise orientation. Preferential streamwise dispersion was duplicated for subsequent large releases with persistent prevailing winds (cases 5 and 6, not shown). In-snow, streamwise plume alignment under a persistent wind regime is an unsurprising result that nevertheless bears reporting because previous studies have lacked a sufficiently dense sensor network to resolve it. Given the Clifton et al. (2008) result that air in permeable media pore space responds to a pressure gradient rather than shear, a persistent in-snow advective flow indicates a persis- 

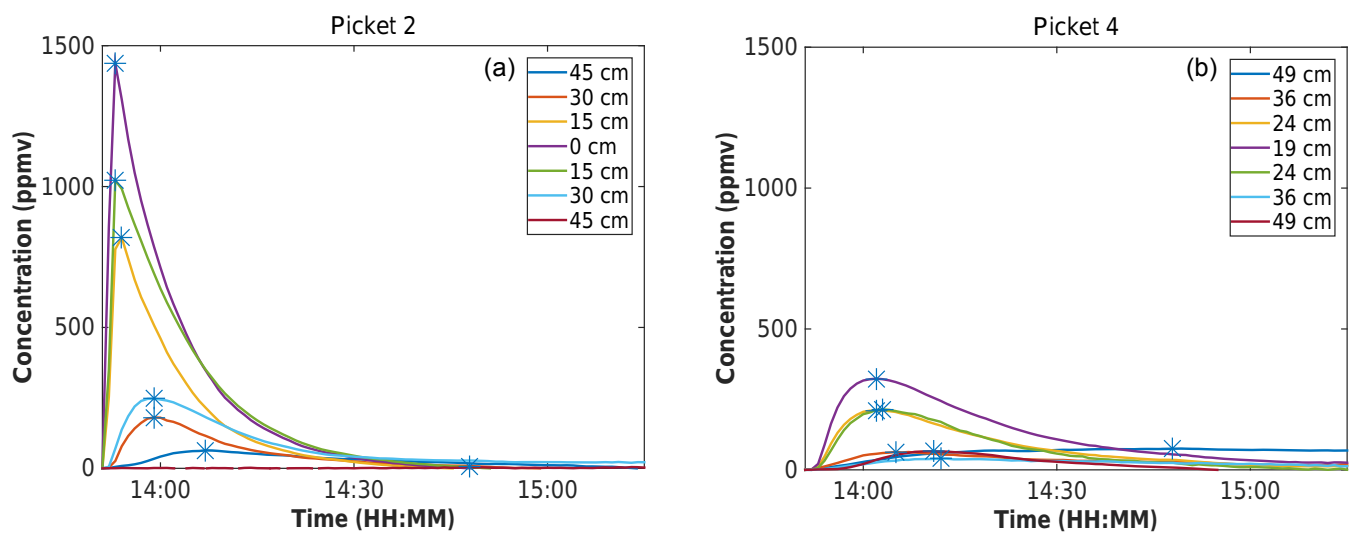

Figure 6. Calibrated near-field breakthrough curves for case 14 (a) and $19 \mathrm{~cm}$ downstream of the release point (b). CO concentration data were acquired at $1 \mathrm{~min}$ resolution. The $\mathrm{CO}$ gas release position is on the opposite side of the picket from the mid-picket $(0 \mathrm{~cm})$ sensor in panel (a) (see also Fig. 2). Distances given in the legend are measured from the release point to the given sensor for both figures. Blue asterisks demark time of maximum concentration at that position.

tent in-snow pressure gradient aligned with the wind direction.

\subsection{Plume propagation given by centroid of mass}

We calculated the displacement of the centroid of mass at each time step as an indicator of advection. The centroid of mass is a more stable measure of plume propagation than the maximum concentration location because the latter may vacillate at each time step when two measurements are nearly the same. In Fig. 8a we plotted the position of plume centroid relative to release position for case 13 , color coded by minute since release. The black asterisk marks the release point. Circles delineate the centroid position at each minute, and the circle diameter is a relative measure of the plume mass-weighted RMS distance from the center of mass. Triangles in Fig. 8a indicate anticipated 1 min translation given by wind direction at $1 / 1000$ of the wind speed. This multiplicative factor $(1 / 1000)$ reduces wind speed to on the order of $\mathrm{mm} \mathrm{s}^{-1}$ - the approximate order of magnitude for air advection in snow (Huwald et al., 2012). We do not account for the mass that advects out of the measurement network because we lack the three-dimensional measurements needed to simultaneously constrain mass loss in the vertical and horizontal directions. Instead, we assume that the centroid position in the horizontal plane is accurate over a short time span between the initial release and the time at which mass starts to advect out of the perimeter of the measurement network.

For the initial several minutes after the release, the calculated centroid position was indeterminate because the sensor at the release position had saturated, returning $\mathrm{NaN}$ (not a number) results. After several minutes more sensors detected the plume, so the centroid position stabilized as it propagated downwind. While propagating downwind some of the plume mass concurrently propagated vertically, out of the sensor network plane. We anticipate that horizontal diffusion was slowed to the degree that the vertical diffusivity exceeded the horizontal diffusivity and the center of mass of the buoyant plume lifted. Numerical simulations similar to those shown in Fig. 4 but using a vertical diffusivity that decreases with snow depth (not shown) are consistent with this hypothesis. After approximately $13 \mathrm{~min}$, the calculated centroid position was driven by the $\mathrm{CO}$ mass still in the horizontal plane and within the sensor network, and the centroid of mass appeared to stall because of the smaller horizontal footprint of the upward moving plume. For the time span between 3 and $13 \mathrm{~min}$, the center of mass advected $6 \mathrm{~cm}$ giving an average velocity of $1.0 \times 10^{-4} \mathrm{~m} \mathrm{~s}^{-1}$, slightly lower than the $1.2 \times 10^{-4} \mathrm{~m} \mathrm{~s}^{-1}$ reported by Huwald et al. (2012) for higher density snow $\left(360 \mathrm{~kg} \mathrm{~m}^{-3}\right)$. We have no measure of specific surface area, which we acknowledge influences permeability (Calonne et al., 2012), and acknowledge the imprecision in the center of mass advection speed determination.

To further assess the influence of wind on plume propagation, we calculated the angle between the propagation of the center of mass and that given by wind direction, again assuming the wind-driven advection speed was $\sim 1 / 1000$ of the wind speed. Results for four representative cases are shown in Fig. 8b. In low-density snow and moderate wind speeds (case 13, $227 \mathrm{~kg} \mathrm{~m}^{-3}$ snow density, $3.41 \mathrm{~m} \mathrm{~s}^{-1}$ wind speed), wind direction was a good predictor for plume propagation direction, even at approximately $20 \mathrm{~cm}$ depth. In denser snow and moderate wind speeds (case $8,430 \mathrm{~kg} \mathrm{~m}^{-3}$ snow density, $2.19 \mathrm{~m} \mathrm{~s}^{-1}$ wind speed), wind direction remained a good predictor for plume propagation direction, with the exceptions that several minutes were required for the plume centroid position to stabilize (as noted in Fig. 8a), and after $\sim 13$ min, by which time snow heterogeneity and vertical dispersion degraded the correlation between wind direction and center of mass propagation direction. For case 11, in which snow density was high and winds were light and variable $\left(430 \mathrm{~kg} \mathrm{~m}^{-3}\right.$ 

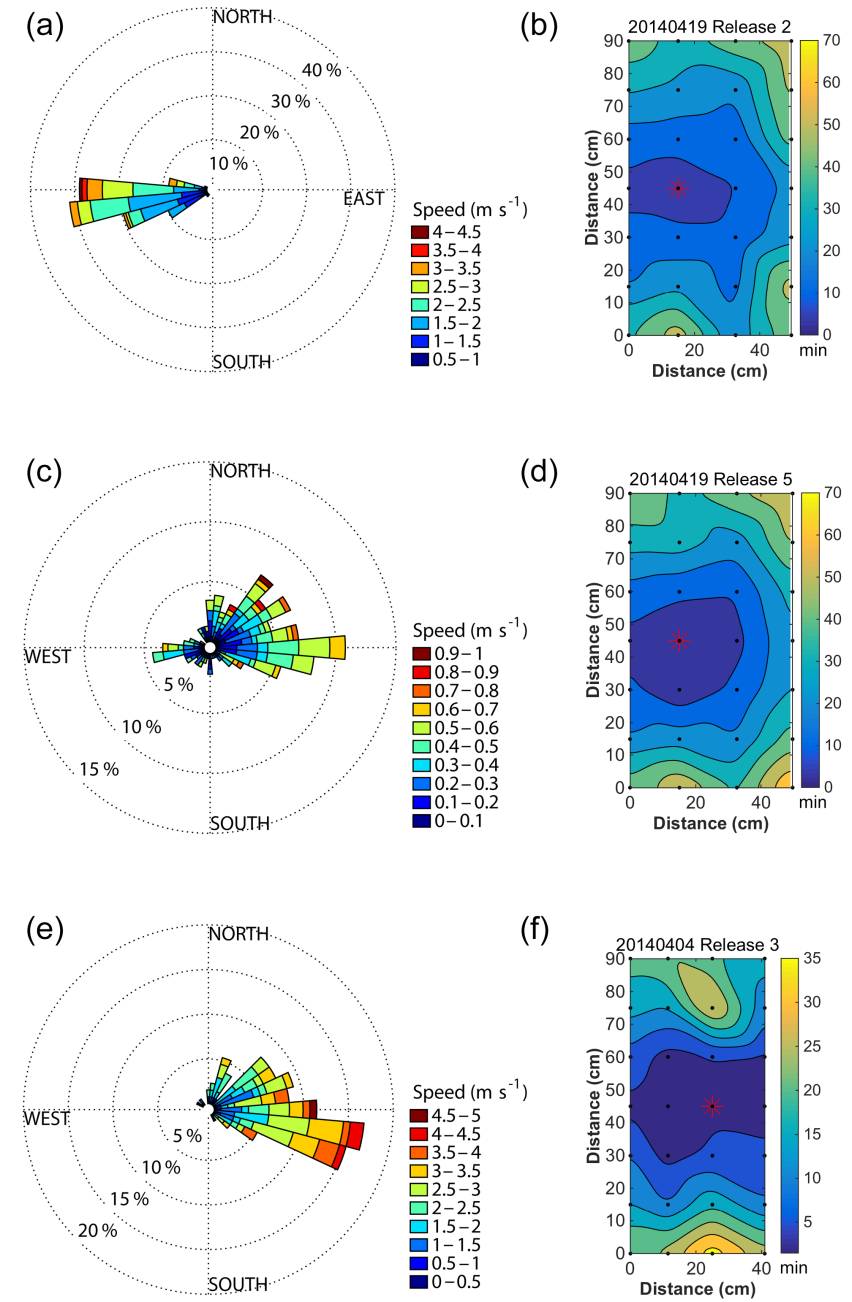

Figure 7. Windrose for persistent wind case 8 in $430 \mathrm{~kg} \mathrm{~m}^{-3}$ snow (a); for light, variable wind case 11 also in $430 \mathrm{~kg} \mathrm{~m}^{-3}$ density snow (c); and for persistent wind with $249 \mathrm{~kg} \mathrm{~m}^{-3}$ density snow case 4 (e). Winds are plotted relative to pickets such that the tops of plots (b), (d) and (f) align with the north direction of the windroses. Wind speed is color coded with speed ranges given in the legend. Time to maximum concentration is color-filled by minutes from release time for case 8 (b), case 11 (d) and case 4 (f). Contours are in $10 \mathrm{~min}$ increments for panels (b) and (d) and $5 \mathrm{~min}$ increments for panel (f). CO sensor positions are marked as black dots and the release point with red asterisks.

snow density, $0.38 \mathrm{~m} \mathrm{~s}^{-1}$ wind speed), the angle between wind direction and plume propagation as indicated by the center of mass was larger and highly variable. For case 12 , in which low-density snow overlaid an ice layer (variable snow density, $4.05 \mathrm{~m} \mathrm{~s}^{-1}$ wind speed), the plume diverged into several preferred pathways (see Sect. 4.6) but the centroid of mass generally advected downwind. These results show that the centroid of mass propagates downwind more reliably in lower density snow than in dense snow, but the centroid of mass propagation direction is not necessarily a reliable indicator of the evolution of the plume footprint.

\subsection{Snow layering}

With the exception of case 12, we deployed our equipment in the topmost layer of a significant snowfall event to minimize the influences of snow layering on plume evolution. We include case 12 because an $18 \mathrm{~cm}$ new snowfall event overlaid a thick $(\sim 5-10 \mathrm{~mm})$ and pervasive layer of refrozen ice, providing an unusual opportunity to study the dispersion signature below a buried, impervious layer where one might expect no advection. The $\mathrm{CO}$ sensor-mounted snow pickets were placed at roughly $18 \mathrm{~cm}$ depth, just below the ice layer. Surface snow was unevenly distributed over the ice layer so picket depths varied by up to $5 \mathrm{~cm}$ but all pickets were positioned at the same depth below the ice layer. Winds were persistently strong from the west (blowing left to right in Fig. 9) during this release. Plume evolution for this case indicates that dispersion not only had molecular diffusion and directional wind signatures but was also characterized by preferential flow regions. We hypothesize that the tracer gas was preferentially following incipient cracks and more porous pathways in the snow layer. This hypothesis is supported by Nachshon et al. (2012), who found that fractures in soil increase permeability by several orders of magnitude and serve as preferred flow pathways in the presence of a mean background flow. From this result we conclude that pressure changes above the snow incite air movement through incipient cracks and porous zones below low permeability ice layers but with less wind-directional influence than that seen for a surface snow layer.

\subsection{Plume propagation given by time to maximum concentration}

Given the previously mentioned deficiencies with computing dispersion enhancement from the centroid of mass velocity, we alternatively investigate dispersion enhancement by comparing measurements with the result given by Eq. (3) using a molecular diffusivity of $\mathrm{CO}$ in snow, $\left(D_{\mathrm{CO}}\right)$, of $2.56 \times 10^{-5} \mathrm{~m}^{2} \mathrm{~s}^{-1}$ (from Huwald et al., 2012). We note that diffusivity of a gas in snow varies with temperature, pressure and snow state. However, these parameters do not vary significantly for different cases obtained during a given experiment deployment. We use the diffusivity, $D\left(t_{\mathrm{MAX}}\right)$, calculated from Eq. (3), and $D_{\mathrm{CO}}$ to estimate the Péclet number:

$P e=\frac{\text { advective transport rate }}{\text { diffusive transport rate }}=\frac{D\left(t_{\mathrm{MAX}}\right)-D_{\mathrm{CO}}}{D_{\mathrm{CO}}}$.

In Eq. (4), we note that measured $D\left(t_{\mathrm{MAX}}\right)$ includes influences of both molecular diffusion and advection so one must subtract the diffusive component, $\left(D_{\mathrm{CO}}\right)$, from the measured $D\left(t_{\mathrm{MAX}}\right)$ to derive the advective component. Since the plume is preferentially spreading vertically, mass is lost from the 

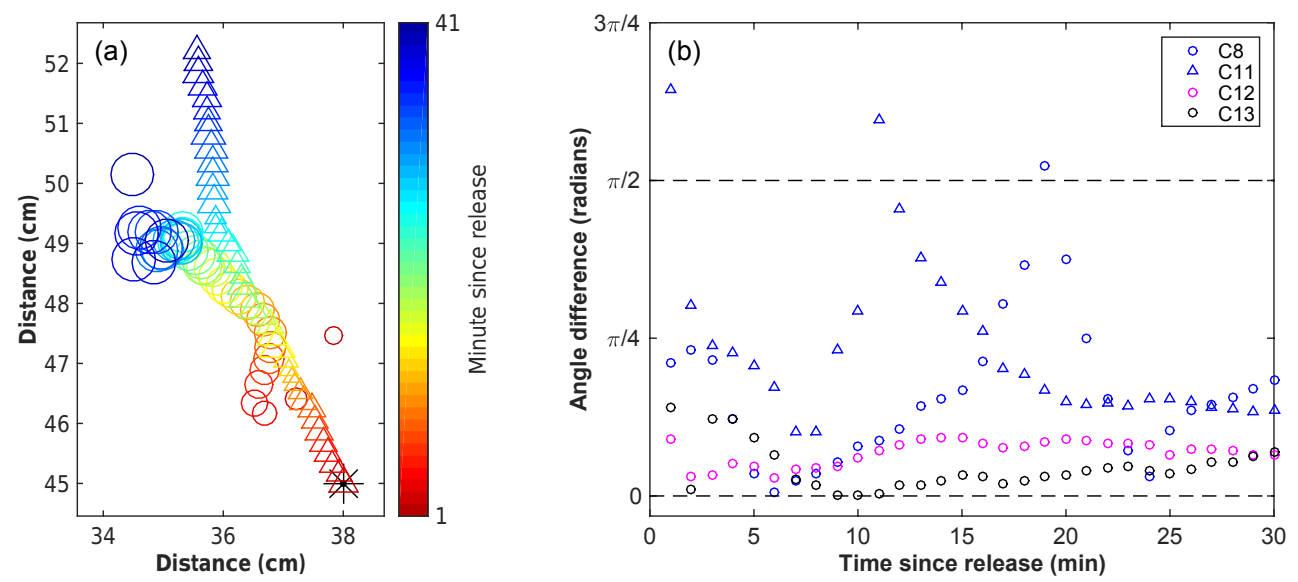

Figure 8. Centroid of mass plotted for case 13 color coded by minute since release (a). A black asterisk marks release position. In panel (b) the angle between the centroid of mass translation direction and the wind direction has higher correspondence in lower density snow (e.g., case 13).

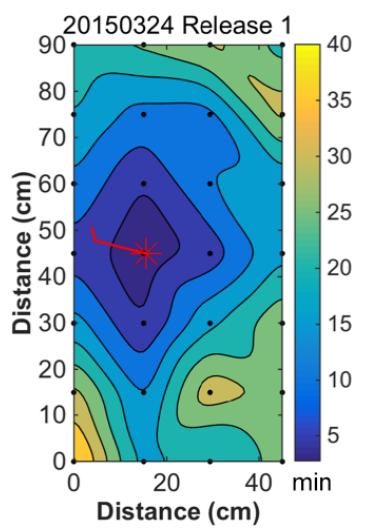

Figure 9. Plot of the time required for $\mathrm{CO}$ to reach maximum concentration for a release with snow pickets placed below an ice layer. The red wind barb indicates the average wind speed (in knots) and direction during the measurement period (see also Table 1). The distance is relative to the bottom and leftmost sensor relative to a coordinate plane viewed from above. The plume has a molecular diffusion signature (roundish), a wind direction signature (downwind propagation) but is also characterized by flow along preferred pathways, which render as irregular lobes at the sensor network resolution.

horizontally oriented measurement network, systematically increasing $t_{\mathrm{MAX}}$ values and thereby decreasing measured effective diffusivity to values smaller than molecular diffusivity. To compensate for the systematic depression of measured effective diffusivity, we find the difference between the smallest calculated effective diffusivity and the molecular diffusivity and normalize the measured effective diffusivity by this difference:

$$
\begin{aligned}
P e_{\text {norm }} & =\frac{D\left(t_{\mathrm{MAX}}\right)+\left[D_{\mathrm{CO}}-\mathrm{MIN}\left(D\left(t_{\mathrm{MAX}}\right)\right)\right]-D_{\mathrm{CO}}}{D_{\mathrm{CO}}} \\
& =\frac{D\left(t_{\mathrm{MAX}}\right)-\operatorname{MIN}\left(D\left(t_{\mathrm{MAX}}\right)\right)}{D_{\mathrm{CO}}} .
\end{aligned}
$$

Our rationale for applying this normalization is that the dispersion of a gas in snow can be no less than the molecular diffusivity. This normalized Péclet number no longer represents the absolute ratio of advective to diffusive transport, but it does preserve a relative measure of advection vs. diffusion and guarantees that the normalized Péclet number is not less than zero. For example, comparing the normalized Péclet number for moderate-wind case $8\left(2.19 \mathrm{~m} \mathrm{~s}^{-1}\right.$ wind speed) in Fig. 10a (see also Fig. 7a-b) with low-wind case 11 $\left(0.38 \mathrm{~m} \mathrm{~s}^{-1}\right.$ wind speed) in Fig. 10b (see also Fig. $7 \mathrm{c}-\mathrm{d}$ ), we note advective signatures streamwise and also along one of the sensor pickets, indicating that leakage along a picket is exacerbated by a wind-induced pressure gradient. The bullseye at the sensor just below the release point in Fig. 10b is an artifact of the release volume rather than advection. The $P e_{\text {norm }}$ gradient is weak in Fig. 10b relative to Fig. 10a as one would expect for a diffusion-dominated regime. Discrepancies from radial symmetry evident in Fig. 10b indicate preferential dispersion pathways along inhomogeneities in the snow layer. Ignoring differences in sensor depth, snow microphysics and high volume release cases (cases 4, 5, 6 and 10 ), the $R^{2}$ correlation was 0.61 between average wind speed and the maximum $P e_{\text {norm }}$ for the remaining cases. This result suggests that in-snow advection increases with wind speed and that snow state and depth in snow tempers the magnitude of in-snow advection in a given layer. A three-dimensional measurement design would improve the quality of the Péclet number values and, accompanied by high-resolution snow characterization, enable absolute comparison of the advec- 

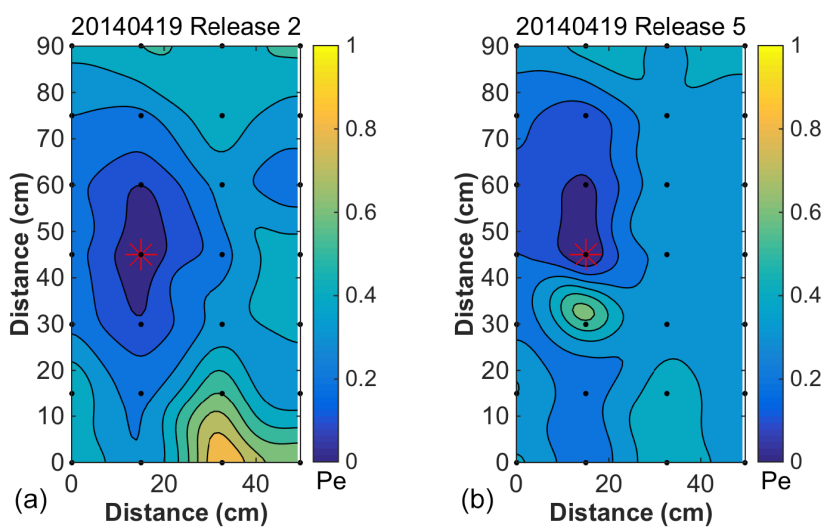

Figure 10. Normalized Péclet number for windy case 8 (a) and lowwind case 11 (b). Both cases were obtained during the same picket deployment. Case 8 shows preferential streamwise dispersion (see also windroses in Fig. 7) as well as enhanced dispersion along high permeability pathways. In panel (b), but for the anomalously large Péclet number gradient just below the release point (due to the release volume), the gradient is weak relative to panel (a), characteristic of a diffusion-dominated regime.

tive vs. diffusive transport in both vertical and horizontal planes.

\section{Conclusions}

Atmospheric pressure gradients can induce subsurface advection that enhances plume dispersion, even in dense snow. Beneath an ice layer the evolution of a tracer gas plume indicates signatures of enhanced diffusion and advection along high permeability pathways in the presence of wind. Over smooth, flat reaches with a prevailing wind, a subsurface plume aligns in a streamwise orientation. Snow inhomogeneities can enhance anisotropic dispersion as wind speed increases, challenging the notion of using a small sample size to represent the intrinsic permeability of snow over broad regions. By comparison of a normalized Péclet number between cases with different wind forcing, we find that variability in the advection signature increases with wind speed.

We were not able to discriminate the relative importance of different processes that enhance in-snow air movement with a 2-D configuration of the sensor network. We anticipate that a modified 3-D deployment design that has a smaller instrument footprint than the snow pickets used in this investigation could discriminate the 3-D evolution of the tracer gas plume. Large ( $\sim$ cubic meter volume), high-resolution representations of permeability are not practical with current technology but in the future would enable one to discriminate between advection and changes in diffusion rate due to permeability changes. Though not available in our tests, we would recommend others employ a blend of $\mathrm{CO}$ with stan- dard air rather than $\mathrm{N}_{2}$, which would then be essentially neutrally buoyant.

Data availability. Data from these experiments may be obtained by corresponding with the first author.

Author contributions. SD, JS and $\mathrm{CH}$ designed the experiments and $\mathrm{SD}$ performed them. SD wrote the original manuscript. JS and $\mathrm{CH}$ edited it.

Competing interests. The authors declare that they have no conflict of interest.

Acknowledgements. We thank Noah Molotch and Michael Durand for organizing deployments at Storm Peak Lab, Colorado. We thank Lisa Dilley and USFS for arranging deployments in Deschutes National Forest, Oregon. Ziru Liu and Rebecca Hochreutener assisted with the field deployments. Finally, we thank Samuel Morin and an anonymous reviewer for their meticulous reviews that substantially improved this manuscript.

Edited by: Joel Savarino

Reviewed by: Samuel Morin and one anonymous referee

\section{References}

Albert, D. G.: Acoustic waveform inversion with application to seasonal snow covers, J. Acoust. Soc. Am., 109, 91-101, https://doi.org/10.1121/1.1328793, 2001.

Albert, M. R.: Modeling heat, mass, and species transport in polar firn, Ann. Glaciol., 23, 138-143, https://doi.org/10.1017/S0260305500013355, 1996.

Albert, M. R.: Effects of snow and firn ventilation on sublimation rates, Ann. Glaciol., 35, 52-56, https://doi.org/10.3189/172756402781817194, 2002.

Albert, M. R. and Hardy, J. P.: Ventilation experiments in a seasonal snow cover, in: Biogeochemistry of Seasonally Snow-Covered Catchments, edited by: Tonnessen, K. A., Williams, M. A., and Tranter, M., Int. Assoc. of Hydrol. Sci. Press, Inst. of Hydrol., Wallingford, UK, 228, 41-49, 1995.

Albert, M. R. and Shultz, E. F.: Snow and firn properties and air-snow transport processes at Summit, Greenland, Atmos. Environ., 36, 2789-2797, https://doi.org/10.1016/S13522310(02)00119-X, 2002

Albert, M. R., Grannas, A. M., Bottenheim, J., Shepson, P. B., and Perron, F. E.: Processes and properties of snowair transfer in the high Arctic with application to interstitial ozone at Alert, Canada, Atmos. Environ., 36, 2779-2787, https://doi.org/10.1016/S1352-2310(02)00118-8, 2002.

Bartlett, S. J. and Lehning, M.: A theoretical assessment of heat transfer by ventilation in homogeneous snowpacks, Water Resour. Res., 47, W04543, https://doi.org/10.1029/2010WR010008, 2011. 
Beavers, G. S. and Joseph, D. D.: Boundary conditions at a naturally permeable wall, J. Fluid Mech., 30, 197-207, https://doi.org/10.1017/S0022112067001375, 1967.

Bowling, D. R. and Massman, W. J.: Persistent wind-induced enhancement of diffusive $\mathrm{CO}_{2}$ transport in a mountain forest snowpack, J. Geophys. Res., 116, G04006, https://doi.org/10.1029/2011JG001722, 2011.

Boxe, C. S. and Saiz-Lopez, A.: Influence of thin liquid films on polar ice chemistry: Implications for Earth and planetary science, Polar Sci., 3, 73-81, https://doi.org/10.1016/j.polar.2009.01.001, 2009.

Buizert, C. and Severinghaus, J. P.: Dispersion in deep polar firn driven by synoptic-scale surface pressure variability, The Cryosphere, 10, 2099-2111, https://doi.org/10.5194/tc-10-20992016, 2016.

Calonne, N., Geindreau, C., Flin, F., Morin, S., Lesaffre, B., Rolland du Roscoat, S., and Charrier, P.: 3-D image-based numerical computations of snow permeability: links to specific surface area, density, and microstructural anisotropy, The Cryosphere, 6, 939-951, https://doi.org/10.5194/tc-6-939-2012, 2012.

Calonne, N., Geindreau, C., and Flin, F.: Macroscopic modeling of heat and water vapor transfer with phase change in dry snow based on an upscaling method: Influence of air convection, J. Geophys. Res.-Earth, 120, 2476-2497, https://doi.org/10.1002/2015JF003605, 2015.

Clarke, G. K. C and Waddington, E. D.: A three-dimensional theory of wind pumping, J. Glaciol., 37, 89-96, 1991.

Clarke, G. K. C., Fisher, D. A., and Waddington, E. D.: Wind pumping: a potentially significant heat source in ice sheets, International Association of Hydrological Sciences Publication, 170, 169-180, 1987.

Clifton, A., Manes, C., Ruedi, J. D., Guala, M., and Lehning, M.: On shear-driven ventilation of snow, Bound.-Lay. Meteorol., 126, 249-261, https://doi.org/10.1007/s10546-007-9235-0, 2008.

Colbeck, S. C.: Air movement in snow due to windpumping, J. Glaciol, 35, 209-213, 1989.

Colbeck, S. C.: The layered character of snow covers, Rev. Geophys., 29, 81-96, 1991.

Courville, Z. R., Albert, M. R., Fahnestock, M. A., Cathles, L. M., and Shuman, C. A.: Impacts of an accumulation hiatus on the physical properties of firn at a lowaccumulation polar site, J. Geophys. Res., 112, F02030, https://doi.org/10.1029/2005JF000429, 2007.

Davis, R. E., Dozier, J., and Perla, R.: Measurement of snow grain, in: Seasonal Snowcovers: Physics, Chemistry, Hydrology, edited by: Jones, H. G. and Orville-Thomas, W. J., D. Reidel Publishing Company, Dordrecht, the Netherlands, 63-74, 1987.

de Lemos, M. J. S. and Silva, R. A.: Turbulent flow over a layer of a highly permeable medium simulated with a diffusion-jump model for the interface, Int. J. Heat Mass Tran., 49, 546-556, https://doi.org/10.1016/j.ijheatmasstransfer.2005.08.028, 2006.

Domine, F. and Shepson, P. B.: Air-snow interactions and atmospheric chemistry, Science, 297, 1506-1510, https://doi.org/10.1126/science.1074610, 2002.

Drake, S. A., Huwald, H., Parlange, M. B., Selker, J. S., Nolin, A. W., and Higgins, C. W.: Attenuation of wind-induced pressure perturbations in alpine snow, J. Glaciol., 62, 674-683, https://doi.org/10.1017/jog.2016.53, 2016.
Drake, S. A., Selker, J. S., and Higgins, C. W.: A low-cost acoustic permeameter, Geosci. Instrum. Method. Data Syst., 6, 199-207, https://doi.org/10.5194/gi-6-199-2017, 2017.

Ebner, P. P., Schneebeli, M., and Steinfeld, A.: Tomographybased monitoring of isothermal snow metamorphism under advective conditions, The Cryosphere, 9, 1363-1371, https://doi.org/10.5194/tc-9-1363-2015, 2015.

Gallet, J.-C., Domine, F., Zender, C. S., and Picard, G.: Measurement of the specific surface area of snow using infrared reflectance in an integrating sphere at 1310 and $1550 \mathrm{~nm}$, The Cryosphere, 3, 167-182, https://doi.org/10.5194/tc-3-167-2009, 2009.

Huwald, H., Selker, J. S., Tyler, S. W., Calaf, M., and Giesen, N. C. v. d.: Carbon monoxide as a tracer of gas transport in snow and other natural porous media, Geophys. Res. Lett., 39, L02504, https://doi.org/10.1029/2011GL050247, 2012.

Massman, W. J. and Frank, J. M.: Advective transport of $\mathrm{CO}_{2}$ in permeable media induced by atmospheric pressure fluctuations: 2. Observational evidence under snowpacks, J. Geophys. Res.Biogeo., 111, G03005, https://doi.org/10.1029/2006JG000164, 2006.

Matzl, M. and Schneebeli, M.: Stereological measurement of the specific surface area of seasonal snow types: Comparison to other methods, and implications for $\mathrm{mm}$ scale vertical profiling, Cold Reg. Sci. Technol., 64, 1-8, https://doi.org/10.1016/j.coldregions.2010.06.006, 2010.

Mößner, M. and Radespiel, R.: Modelling of turbulent flow over porous media using a volume averaging approach and a Reynolds stress model, Comput. Fluids, 108, 25-42, https://doi.org/10.1016/j.compfluid.2014.11.024, 2015.

Nachshon, U., Dragila, M., and Weisbrod, N.: From atmospheric winds to fracture ventilation: Cause and effect, J. Geophys. Res., 117, G02016, https://doi.org/10.1029/2011JG001898, 2012.

Neumann, T. A., Albert, M. R., Engel, C., and Courville, Z.: Sublimation rate and the mass-transfer coefficient for snow sublimation, Int. J. Heat Mass Tran., 52, 309-315, https://doi.org/10.1016/j.ijheatmasstransfer.2008.06.003, 2009.

Painter, T. H., Molotch, N. P., Cassidy, M., Flanner, M., and Steffen, K.: Contact spectroscopy for determination of stratigraphy of snow optical grain size, J. Glaciol., 53, 121-127, https://doi.org/10.3189/172756507781833947, 2007.

Paw U, K. T., Ideris, J., Matista, A., Rolston, D. E., Hsiao, T. C., Kochendorfer, J., Wharton, S., and Pyles, R. D.: Pressure Pumping Effects on Soil Efflux Measurements of $\mathrm{CO}_{2}$, 2001-2006 MissionKearney Foundation of Soil Science: Soil Carbon and California's Terrestrial Ecosystems Final Report: 2002024, 1/1/2003-12/31/2004, Kearney Foundation of Soil Science, Davis, California, USA, 2004.

Pinzer, B. R., Kerbrat, M., Huthwelker, T., Gäggeler, H. W., Schneebeli, M., and Ammann, M.: Diffusion of $\mathrm{NO}_{x}$ and HONO in snow: A laboratory study, J. Geophys. Res.-Atmos., 115, D03304, https://doi.org/10.1029/2009JD012459, 2010.

Scheidegger, A. E.: Statistical hydrodynamics in porous media, J. Appl. Phys., 25, 994-1001, https://doi.org/10.1063/1.1721815, 1954.

Seok, B., Helmig, D., Williams, M. W., Liptzin, D., Chowanski, K., and Hueber, J.: An automated system for continuous measurements of trace gas fluxes through snow: an evaluation of the gas diffusion method at a subalpine forest 
site, Niwot Ridge, Colorado, Biogeochemistry, 95, 95-113, https://doi.org/10.1007/s10533-009-9302-3, 2009.

Severinghaus, J. P., Albert, M. R., Courville, Z .R., Fahnestock, M. A., Kawamura, K., Montzka, S. A., Mühle, J., Scambos, T. A., Shields, E., Shuman, C. A., and Suwa, M.: Deep air convection in the firn at a zero-accumulation site, central Antarctica, Earth Planet. Sc. Lett., 293, 359-367, https://doi.org/10.1016/j.epsl.2010.03.003, 2010.

Socolofsky, S. A. and Jirka, G. H.: Special topics in mixing and transport processes in the environment, Engineering Lectures, 5th Edition, Texas A\&M University, College Station, Texas, USA, 2005.

Sokratov, S. A. and Sato, A.: Wind propagation to snow observed in laboratory, Ann. Glaciol., 31, 427-433, https://doi.org/10.3189/172756400781820020, 2000.
Sturm, M. and Johnson, J. B.: Natural convection in the subarctic snow cover, J. Geophys. Res.-Solid, 96, 11657-11671, https://doi.org/10.1029/91JB00895, 1991.

Tape, K. D., Rutter, N., Marshall, H. P., Essery, R., and Sturm, M.: Recording microscale variations in snowpack layering using near-infrared photography, J. Glaciol., 56, 75-80, https://doi.org/10.3189/002214310791190938, 2010.

Waddington, E. D., Cunningham, J., and Harder, S. L.: The Effects Of Snow Ventilation on Chemical Concentrations, in: Chemical Exchange Between the Atmosphere and Polar Snow, edited by: Wolff, E. W. and Bales, R. C., NATO ASI Series, 43, Springer, Berlin, Germany, 403-452, 1996.

Wallace, J. M. and Hobbs, P. V.: Atmospheric science: an introductory survey, Academic press, Burlington, MA, USA, vol. 92, 483 pp., 2006. 